\title{
SISTEM MANAJEMEN PENGADAAN LABORATORIUM: ANALISIS KEBUTUHAN SISTEM DARI PERSPEKTIF STAKEHOLDER
}

\author{
Rayinda Pramuditya Soesanto* \\ Fakultas Rekayasa Industri, Universitas Telkom, Jl. Telekomunikasi, Terusan Buah Batu, Bandung, \\ Jawa Barat, Indonesia 40257
}

(Received: March 21, 2019/Accepted: April 1, 2020)

\begin{abstract}
Abstrak
Dalam fase merancang sistem informasi, terutama pada sistem informasi manajemen, menambahkan perspektif pelanggan merupakan hal yang mendasar. Dari sektor edukasi terutama universitas, laboratorium bertindak sebagai bagian utama dari aktivitas universitas. Aktivitas laboratorium seperti praktikum dan kegiatan administratif lainnya seringkali membutuhkan banyak waktu untuk mempersiapkannya terutama dalam proses pengadaan, tetapi dalam kenyataan proses pengadaan dari laboratorium membutuhkan usaha dan waktu lebih serta pihak laboratorium pun tidak dapat melacak kondisi dari proses pengadaan bagian logistikfakultas. Penelitian ini bertujuan untuk menentukan dan memprioritaskan voice of customer dalam merancang sistem manajemen pengadaan menggunakan dimensi kualitas informasi. Metode Waterfall digunakan dalam fase pengembangan dan focus group discussion dilaksanakan untuk melakukan pengurutan voice of customer. Penelitian ini dilakukan di Fakultas Rekayasa Industri Universitas Telkom. Hasil dari focus group discussion menyarankan agar "Service performance is reliable", "Information is realtime" dan "The Information System help organizational business process" sebagai tiga hal teratas yang harus diprioritaskan dalam merancang sistem manajemen pengadaan laboratorium. Penelitian lebih lanjut yang dapat dilakukan adalah merancang sistem pengadaan laboratorium berdasarkan hasil dari penelitian ini.
\end{abstract}

Kata kunci: Analisis Kebutuhan; E-Procurement; Laboratorium; Voice of Customer

\begin{abstract}
[Title: laboratory Procurement System: A Requirement Analysis from stakeholder perspective] In the designing phase of the information system, especially management information system, adding the customer point of view is an essential part. In educational sector especially in the university, laboratory acts as the main part of universities activity. Activity in the laboratory process often needs a lot of time to prepare especially in the procurement process, but in reality, the process of procurement from laboratory takes a lot of effort and time and the laboratory unable to track down the status of the procurement to Faculty Logistic. This research purpose is to determine and prioritize the voice of the customer in designing laboratory asset management system by using quality dimension for information. Waterfall method is used for the development phase and focuses group discussion is being held for ranking the voice of the customer. This research is conducted in the School of Industrial Engineering Telkom University. The result suggest that "Service performance is reliable", "Information is realtime" and "The Information System help organizational business process" are the top three that must be prioritized in designing the laboratory asset management system.
\end{abstract}

Keywords: Laboratory; Requirement Analysis; E-Procurement; Voice of Customers

\section{Pendahuluan}

Sistem informasi manajemen adalah sistem terintegrasi yang menjadi pendukung operasional, manajemen dan fungsi pengambilan keputusan dari sebuah

*Penulis Korespondensi.

E-mail: raysoesanto@telkomuniversity.ac.id organisasi (Turban, Aronson, \& Liang, 2005). Penelitian terbaru menunjukan bahwa kualitas dan strategi dari sistem informasi manajemen berkembang secara signifkan terhadap keuntungan dari suatu korporasi (Pérez-Méndez \& Machado-Cabezas, 2014). Dari sektor edukasi terutama di tingkat universitas, laboratorium memiliki peran utama dalam aktivitas tersebut. Aktivitas di laboratorium seperti praktikum dan hal bersifat administratif lainnya seringkali 
membutuhkan waktu yang cukup lama terutama dalam proses pengadaan laboratorium. Proses pengadaan merupakan proses terukur untuk mengadakan keperluan suatu barang ataupun jasa yang sesuai dengan spesifikasi yang diinginkan. Proses pengadaan dengan menggunakan bantuan sistem informasi dapat mempermudah proses dan juga menghilangkan proses yang tidak efisien (Mose, Njihia, \& Magutu, 2013).
Pada Fakultas Rekayasa Industri Universitas Telkom, proses pengadaan laboratorium seringkali dieksekusi dengan metode konvensional. Permintaan pengadaan barang dari laboratorium harus melampirkan surat permintaan yang ditujukan kepada staf logistik fakultas dan diteruskan ke bagian pengadaan universitas. Apabila disetujui, maka barang akan dipesan dan didistribusikan ke laboratorium. Proses bisnis existing pengadaan laboratorium dapat dilihat di Gambar 1.

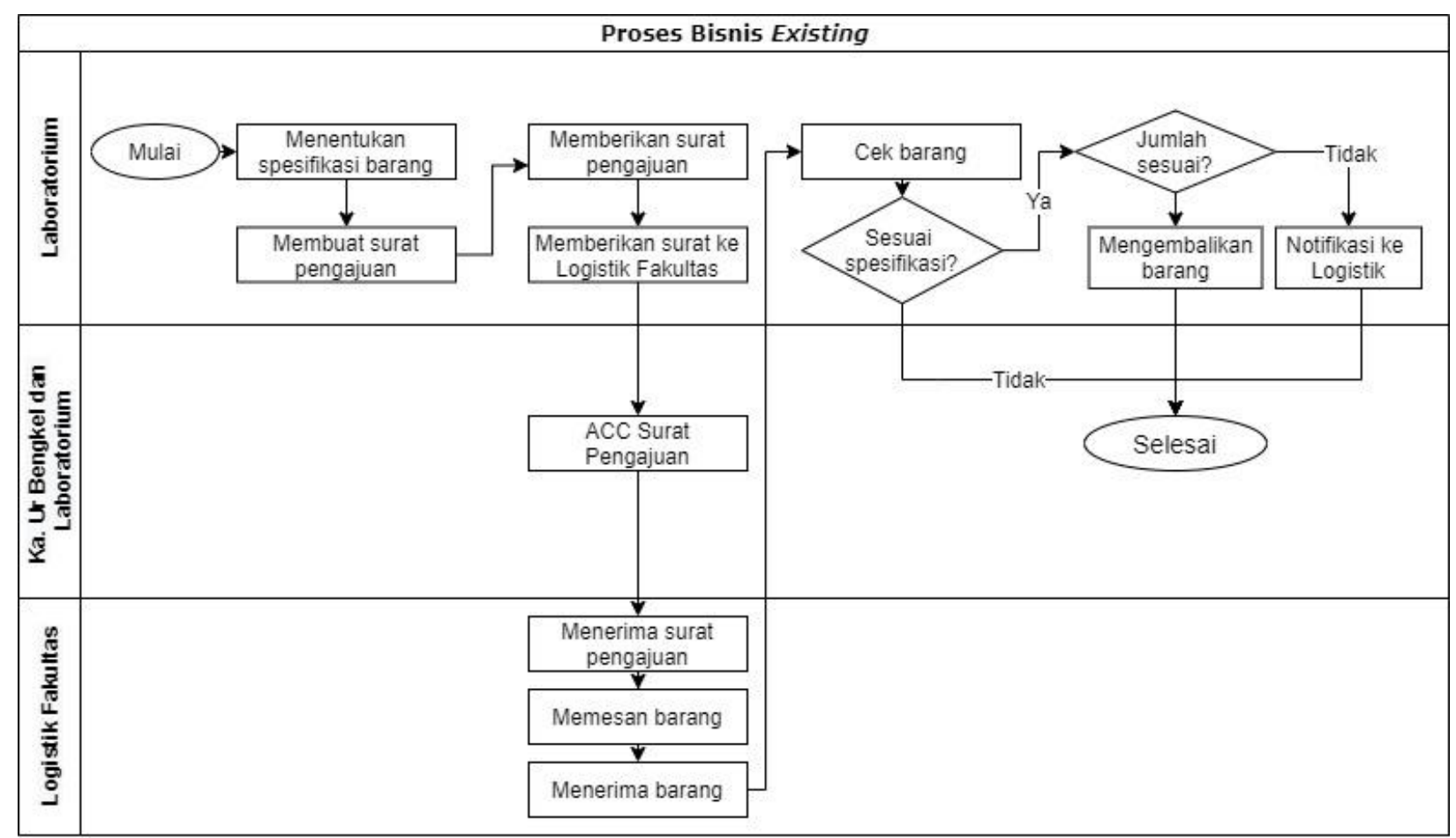

Gambar 2. Respon Kepuasan Layanan Inventaris Laboratorium

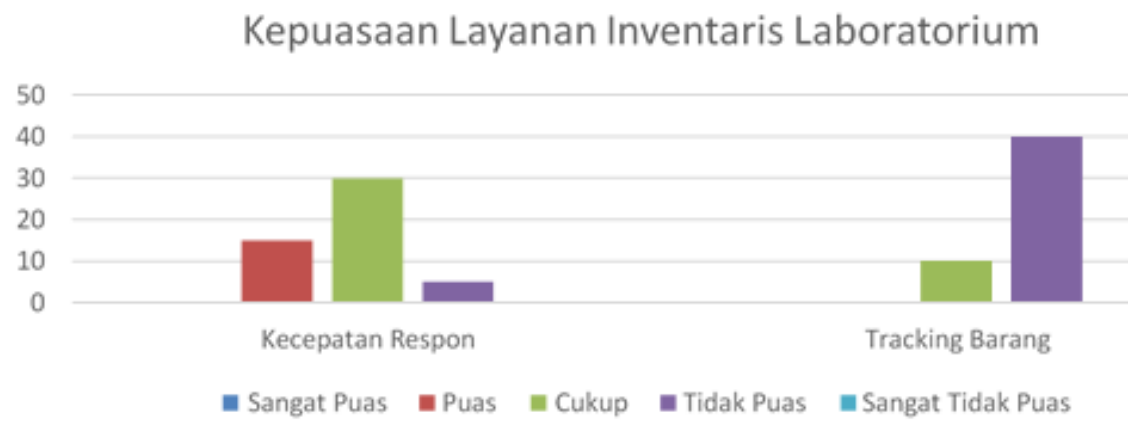

Gambar 1. Proses Bisnis Saat Ini

Masalah yang muncul dari alur proses bisnis ini terletak pada pihak laboratorium yang tidak dapat melacak proses pengadaan yang dipesan secara langsung. Masalah lain yang seringkali timbul terletak pada ketidaksesuaian barang yang dipesan dengan spesifikasi yang diberikan laboratorium. Gambar 2 menunjukkan hasil survei pendahuluan mengenai kepuasan layanan inventaris laboratorium. Data yang didapatkan berasal dari survei kepada 3 perwakilan dari tiap laboratorium di Fakultas Rekayasa Industri.
Berdasarkan perspektif manajerial, proses bisnis yang ada saat ini memakan waktu dan tidak efektif. Untuk menghadapi masalah tersebut, sistem informasi menjadi penting bagi kegiatan operasional fakultas. Sistem informasi untuk memantau proses pengadaan secara elektronik sangat dibutuhkan, karena banyak keuntungan dengan menggunakan sistem tersebut terutama dalam bidang pengadaan. Sistem informasi merupakan sebuah sistem yang terintegrasi yang menyediakan informasi untuk membantu fungsi operasional, manajemen, dan pengambilan keputusan dari sebuah organisasi (O'Brien \& Marakas, 2012). Menurut 
Petter, DeLone dan McLean (2008), keuntungan dari digunakannya sistem informasi adalah dapat mengurangi biaya, meningkatkan produktivitas dan meningkatkan efektivitas pengambilan keputusan. Menurut Laudon dan Laudon (2016), keuntungan dari digunakannya sistem informasi manajemen adalah menghilangkan pekerjaan administratif, selain itu sistem informasi manajemen juga dapat menjadikan organisasi lebih efektif dengan empowering dan enhancing deskripsi kerja dari karyawan.

Untuk memastikan bahwa sistem informasi manajemen yang akan diimplementasikan pada kasus ini sesuai keinginan, analisis perlu dilakukan pada fase perancangan untuk menentukan indikator apa saja yang diinginkan dan dibutuhkan oleh pelanggan. Untuk mendapatkan jawaban atas pertanyaan tersebut, pendapat pelanggan dibutuhkan dalam merancang sistem informasi manajemen berdasarkan sudut pandang pelanggan. Penelitian ini merupakan pengembangan dari penelitian sebelumnya yang dilakukan oleh Soesanto dkk. (2013) untuk dimensi kualitas dan Soesanto dkk. (2014), (2016) dalam menentukan bentuk prioritas House of Quality. Menurut Daellenbach dan McNickle (2013), stakeholder merupakan seseorang atau lebih yang mempunyai kepentingan terhadap suatu permasalahan. Stakeholder yang dimaksud di penelitian ini adalah orang yang berkepentingan dalam proses pengadaan barang laboratorium di Fakultas Rekayasa Industri, Universitas Telkom. Semua stakeholder yang terlibat di proses pengadaan menjadi responden di penelitian ini. Tabel 1 menunjukkan stakeholder dari proses pengadaan barang laboratorium.

Tabel 1. Stakeholder Proses Pengadaan Barang Laboratorium

\begin{tabular}{|c|c|c|}
\hline No & Stakeholder & Penjelasan \\
\hline 1 & $\begin{array}{l}\text { Asisten } \\
\text { laboratorium }\end{array}$ & $\begin{array}{l}\text { Sebagai pengguna barang } \\
\text { di laboratorium }\end{array}$ \\
\hline 2 & Laboran & $\begin{array}{l}\text { Sebagai bagian operasional } \\
\text { dari pihak fakultas yang } \\
\text { mengurusi masalah } \\
\text { administrasi laboratorium }\end{array}$ \\
\hline 3 & $\begin{array}{l}\text { Ka. Ur } \\
\text { Bengkel dan } \\
\text { Laboratorium }\end{array}$ & $\begin{array}{l}\text { Sebagai manajer } \\
\text { laboratorium }\end{array}$ \\
\hline 4 & $\begin{array}{l}\text { Logistik } \\
\text { Fakultas }\end{array}$ & $\begin{array}{l}\text { Sebagai pengeksekusi } \\
\text { permintaan barang dari } \\
\text { fakultas }\end{array}$ \\
\hline 5 & $\begin{array}{l}\text { Wakil Dekan } \\
\text { II bagian } \\
\text { Sumberdaya } \\
\text { dan Keuangan }\end{array}$ & $\begin{array}{l}\text { Sebagai struktur tertinggi } \\
\text { dalam proses pengadaan } \\
\text { barang }\end{array}$ \\
\hline 6 & $\begin{array}{l}\text { Staff } \\
\text { Keuangan } \\
\text { Fakultas }\end{array}$ & $\begin{array}{l}\text { Sebagai bagian fakultas } \\
\text { yang menerima invoice dan } \\
\text { membayarkan invoice } \\
\text { pengadaan barang }\end{array}$ \\
\hline
\end{tabular}

Penelitian ini bertujuan untuk merancang kebutuhan sistem manajemen pengadaan laboratorium yang dapat memenuhi ekspektasi stakeholder. Di penelitian ini, seluruh stakeholder yang terlibat dalam pengadaan barang dijadikan sebagai responden. Penelitian yang dilakukan sebelumnya oleh Saxena dan Agarwal (2018) berfokus pada faktor yang berpengaruh terhadap aplikasi e-procurement. Penelitian yang dilakukan oleh Sharma dan Pandey (2016) berfokus pada metode-metode requirement analysis dalam perancangan sebuah software. Penelitian yang dilakukan oleh Ahmadi, Pishvaee, dan Torabi (2018) berfokus pada perancangan kebutuhan sistem procurement untuk di rumah sakit. Penelitian yang dilakukan oleh Seo, Tan, dan Warman (2018) berfokus pada requirement sistem procurement untuk pemerintahan di Indonesia.

\section{Metode Penelitian}

Tujuan dari penelitian ini adalah untuk menentukan requirement dalam bentuk indikator apa saja yang diinginkan dan dibutuhkan yang dapat memenuhi ekspektasi stakeholder untuk sistem pengadaan laboratorium. Pada penelitian ini, dimensi kualitas digunakan untuk menentukan karakteristik yang khusus dari sistem informasi yang dibangun menggunakan dimensi kualitas berdasarkan Soesanto dkk. (2013). Pada dasarnya sebuah sistem informasi memiliki siklus hidup, yang dimulai dari penentuan kebutuhan hingga pada tahapan operational dan maintenance agar sistem informasi dapat diandalkan, untuk menggambarkan tahapan-tahapan tersebut maka akan lebih mudah bila digambarkan dalam model Waterfall. Model ini menggunakan pendekatan berurutan dari fase kebutuhan sistem hingga maintenance. Setiap tahapan didetailkan secara jelas dan runtun sehingga mempermudah dalam proses perancangan sistem (Sommerville, 2009). Gambar 3 menunjukkan keseluruhan proses dari metode waterfall. Pada penelitian ini, requirement definition menjadi fokus utama penelitian dengan mendetailkan kebutuhan dari setiap stakeholder agar nantinya sistem informasi yang dirancang sesuai dengan ekpektasi para stakeholder.

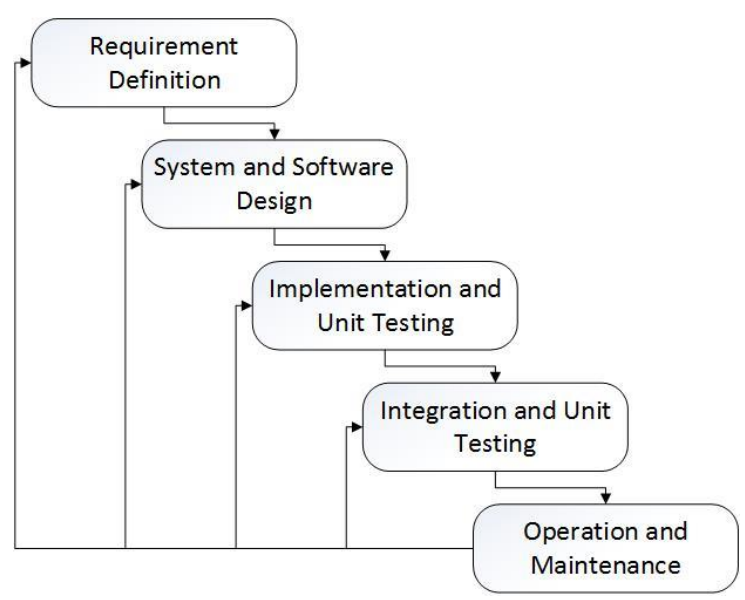

Gambar 3. Metode Waterfall (Sommerville, 2009)

Dalam merancang sistem informasi, langkah pertama yang perlu dilakukan adalah menentukan kebutuhan, pada fase inilah penelitian ini difokuskan. Langkah pertama dimulai dengan menentukan voice of customer sebagai dasar dalam merancang sistem 
informasi. Voice of customer didapatkan dari dimensi kualitas penelitian sebelumnya (Soesanto, Utama, \& Kurniawati, Pengukuran Kualitas Sistem Informasi Laboratorium, 2013). Dimensi kualitas, seperti voice of cutomer kemudian diubah menjadi karakteristik teknis dan prioritas berdasarkan sudut pandang stakeholder. Langkah selanjutnya adalah menentukan responden untuk penelitian ini, empat responden yang dipilih berasal dari stakeholder, alasan utama pemilihan empat responden tersebut adalah karena keempat stakeholder tersebut terlibat dalam proses pengadaaan barang laboratorium. Setelah responden didapatkan, maka langkah selanjutnya adalah mengumpulkan data, data dikumpulkan melalui proses focus group discussion (FGD) kepada responden. FGD dilakukan untuk mengetahui lebih detail mengenai poin-poin penting yang perlu diperhatikan dalam merancang sistem pengadaan laboratorium. Focus group discussion yang dilakukan berlangsung pada bulan Januari hingga Februari 2018. Setelah data didapatkan, maka langkah selanjutnya adalah melakukan ranking dari setiap karakteristik teknis untuk menentukan prioritas.

Dari penelitian yang sebelumnya (Soesanto, Utama, \& Kurniawati, Pengukuran Kualitas Sistem Informasi Laboratorium, 2013) didapatkan dimensi kualitas yang digunakan dalam penelitian ini. Tabel 2 menunjukkan dimensi kualitas sistem informasi yang digunakan.

Tabel 2. Dimensi Kualitas Sistem Informasi (Soesanto, Utama, \& Kurniawati, 2013)

\begin{tabular}{cl}
\hline No. & \multicolumn{1}{c}{ Dimensi } \\
\hline 1 & Reliability \\
2 & Efficiency \\
3 & Security and privacy \\
4 & Ease of use \\
5 & Apperance \\
6 & Content \\
7 & Effectiveness \\
8 & Customizable \\
9 & Maintainability \\
\hline
\end{tabular}

Dimensi Reliability merupakan dimensi yang berhubungan dengan keandalan suatu sistem informasi. Keandalan mempunyai atribut services performance is reliable, Fault Tolerance, Information is real time, dan Information is believable. Dimensi Efficiency merupakan dimensi yang menjelaskan mengenai apakah suatu sistem informasi menggunakan resource yang optimal. Dimensi support merupakan dimensi yang berhubungan dengan bantuan yang disediakan sistem informasi untuk pelanggan, termasuk di dalamnya adalah dokumen-dokumen perancangan sistem informasi seperti proses bisnis, organisasi. Indikator dalam dimensi ini adalah availability of website usage information, dan availability of troubleshooting service. Dimensi security and privacy merupakan komponen utama dalam perancangan sebuah sistem informasi agar sistem informasi yang dirancang aman dan gangguan sistem informasi dapat terjaga privasinya. Dalam dimensi ini, yang menjadi indikatornya adalah the data is encrypted, the information system ability to safeguard, user has an account dan user has limitation access.

Dimensi ease of use merupakan dimensi yang mendefinisikan kemudahan dalam penggunaan sistem informasi merupakan sesuatu yang diharapkan oleh pengguna, maka dari itu sebuah sistem informasi harus dirancang agar sesuai dengan keinginan pengguna. Dalam penentuan tingkat sistem informasi yang baik, indikatornya adalah the information system can be accessed everywhere, the information system can be accessed from other platform, the newest's information notification is available, dan the Information System is available in many languages. Dimensi appearance merupakan dimensi yang berfokus pada tampilan suatu sistem, tampilan suatu sistem informasi sangat berpengaruh pada tingkat penerimaan pengguna terhadap sistem informasi. Indikator yang digunakan adalah The information system is unsightly, dan The text is easy to read. Dimensi content merupakan merupakan hal utama yang harus diperhatikan ketika melakukan perancangan sistem informasi karena merupakan isi dari sebuah sistem yang dibangun. Pada dimensi ini yang menjadi indikatornya adalah The information system allow users to access the content easily, dan the information provided is easy to understand.

Dimensi effectiveness merupakan dimensi yang berhubungan dengan ekspektasi stakeholder agar sistem informasi yang dibuat sesuai dengan requirement yang diinginkan. Atribut yang digunakan adalah sistem informasi dibuat sesuai requirement. Selain itu dapat juga disesuaikan dengan budaya organisasi yang berlaku dimana sistem informasi tersebut dibuat. Indikator dari dimensi adalah the Information System meets the objective dan the information system suitable for the organization. Customizable merupakan dimensi yang berhubungan dengan kemudahan user dan sistem informasi dalam mengikuti perubahan kondisi baik dari eksternal maupun internal. Indikator dari dimensi ini adalah user can edit personal data, user can find out the data that had entered, dan the information system can adapt change in policy. Maintainability merupakan dimensi yang menjelaskan bagaimana suatu sistem dikatakan baik dari tingkat frekuensi maintenance-nya. Indikator dari dimensi ini adalah the information system is stable dan the information system is easy to maintain.

\section{Hasil dan Pembahasan}

Pada fase ini, hasil dari FGD menjadi poin utama, hasil tersebut akan dipertimbangkan untuk pengembangan lebih lanjut dari sistem manajemen pengadaan laboratorium. Dari Soesanto dkk. (2013) terdapat 11 dimensi kualtias yang digunakan yaitu reliability, efficiency, support, security and privacy, ease of use, appearance, content, effectivity, acceptability, customizable, dan maintainability. Kualitas dimensi tersebut kemudian diubah menjadi voice of customer (VOC), VOC kemudian diprioritaskan oleh stakeholder dari peringkat 1 sampai dengan 11. Hasil prioritas tersebut 
kemudian menjadi dasar acuan dalam merancang sistem informasi pengadaan laboratorium. FGD yang dilakukan berlangsung pada bulan Januari hingga Februari 2018 diikuti oleh asisten laboratorium, laboran, kepala urusan laboratorium Fakultas Rekayasa Industri, dan bagian logistik fakultas.

\section{A. Analisis Dimensi Kualitas}

Untuk dimensi reliability, dari hasil FGD, dapat diketahui bahwa VOC service performance is reliable menempati peringkat pertama, sehingga VOC tersebut harus diprioritaskan dalam merancang sistem pengadaan laboratroium. Tabel 3 menunjukkan ranking voice of customer hasil FGD dimensi reliability.

Tabel 3. Ranking Voice Of Customer Hasil FGD Dimensi Reliability

\begin{tabular}{|c|c|c|}
\hline No. & VOC & Ranking \\
\hline 1 & $\begin{array}{l}\text { Services performance is } \\
\text { reliable }\end{array}$ & 1 \\
\hline 2 & Information is real time & 2 \\
\hline 3 & Information is believable & 7 \\
\hline
\end{tabular}

Untuk dimensi efficiency, dari hasil FGD, dapat diketahui bahwa VOC one data entry for all purpose menempati peringkat ke 5, hasil dari VOC tersebut mengindikasikan bahwa dimensi efisiensi masih dianggap penting oleh para stakeholder sehingga dimensi tersebut dijadikan pertimbangan penting ketika merancang sistem pengadaan laboratorium.

Tabel 4. Ranking Voice Of Customer Hasil FGD Dimensi Efficiency

\begin{tabular}{cc}
\hline VOC & Ranking \\
\hline One data entry for all purpose & 5 \\
\hline
\end{tabular}

Untuk dimensi support, dari hasil FGD, dapat diketahui bahwa VOC dari dimensi support berada di peringkat 10 ke bawah, ini menandakan para stakeholder merasa dimensi support sebagai bagian yang penting namun bukan prioritas utama. Tabel 5 menunjukan ranking voice of customer hasil FGD dimensi support.

Tabel 5. Ranking Voice Of Customer Hasil FGD Dimensi Support

\begin{tabular}{clc}
\hline No. & \multicolumn{1}{c}{ VOC } & Ranking \\
\hline 1 & $\begin{array}{l}\text { Availability of website } \\
\text { usage information } \\
\text { Availability of } \\
\text { troubleshooting service }\end{array}$ & 20 \\
\hline
\end{tabular}

Untuk security and privacy, dari hasil FGD, dapat diketahui bahwa dimensi security and privacy tidak menjadi prioritas utama bagi stakeholder. Dari hasil FGD, untuk dimensi ease of use dapat diketahui bahwa VOC The Information system can be accessed everywhere menjadi hal yang penting bagi para stakeholder, hal ini dikarenakan akan lebih mudah bagi para pengguna sistem untuk dapat mengakses sistem darimana saja dan kapan saja ketika dibutuhkan. Tabel 7 menunjukan ranking voice of customer hasil FGD dimensi ease of use.

Tabel 6. Ranking Voice Of Customer Hasil FGD Dimensi Security And Privacy

\begin{tabular}{lc}
\multicolumn{2}{c}{ Dimensi Security And Privacy } \\
\hline \multicolumn{1}{c}{ VOC } & Ranking \\
\hline $\begin{array}{l}\text { The information system ability to } \\
\text { safeguard }\end{array}$ & 19 \\
\hline
\end{tabular}

Tabel 7. Ranking Voice Of Customer Hasil FGD Dimensi Ease Of Use

\begin{tabular}{clc}
\hline No. & \multicolumn{1}{c}{ VOC } & Ranking \\
\hline 1 & $\begin{array}{l}\text { The Information system can } \\
\text { be accessed everywhere } \\
\text { The Information system can }\end{array}$ & 4 \\
2 & $\begin{array}{l}\text { be accessed from other } \\
\text { platform } \\
\text { The Newest's information } \\
\text { notification is available }\end{array}$ & 15 \\
4 & $\begin{array}{l}\text { The Information System is } \\
\text { available in many languages }\end{array}$ & 21 \\
\hline
\end{tabular}

Dari hasil FGD, untuk dimensi appearance dapat diketahui bahwa dimensi appearance tidak menjadi hal yang penting bagi stakeholder, ini dikarenakan semua stakeholder merasa konten utama dari sistem lebih penting dibandingkan dengan tampilan dari sistem yang akan dirancang. Tabel 8 menunjukkan ranking voice of customer hasil FGD dimensi appearance

Tabel 8. Ranking Voice Of Customer Hasil FGD Dimensi Appearance

\begin{tabular}{clc}
\hline No. & \multicolumn{1}{c}{ VOC } & Ranking \\
\hline 1 & $\begin{array}{l}\text { The information system } \\
\text { is unsightly }\end{array}$ & 14 \\
2 & The text is easy to read & 13 \\
\hline
\end{tabular}

Dari hasil FGD, untuk dimensi content dapat diketahui bahwa VOC The information system allow users to access the content dan Information provided is easy to understand masuk ke 10 besar peringkat prioritas yang diinginkan oleh stakeholder. Tabel 9 menunjukkan ranking voice of customer hasil FGD dimensi content.

Tabel 9. Ranking Voice Of Customer Hasil FGD Dimensi Content

\begin{tabular}{clc}
\hline No. & \multicolumn{1}{c}{ VOC } & Ranking \\
\hline 1 & $\begin{array}{l}\text { The information system } \\
\text { allow users to access the } \\
\text { content }\end{array}$ & 8 \\
2 & $\begin{array}{l}\text { Information provided is } \\
\text { easy to understand }\end{array}$ & 10 \\
\hline
\end{tabular}

Untuk dimensi effectiveness, dapat diketahui bahwa VOC The Information System help 
organizational business process menjadi hal yang penting bagi stakeholder.

Tabel 10. Ranking Voice Of Customer Hasil FGD Dimensi Effectiveness

\begin{tabular}{lc}
\hline \multicolumn{1}{c}{ VOC } & Ranking \\
\hline $\begin{array}{l}\text { The Information System help } \\
\text { organizational business process }\end{array}$ & 3 \\
\hline
\end{tabular}

Dari hasil FGD, untuk dimensi acceptability dapat diketahui bahwa VOC The Information System meets the objective menempati peringkat ke 6 , dari hasil peringkat yang diberikan oleh stakeholder maka dapat ditarik kesimpulan bahwa VOC tersebut menjadi hal yang penting menurut stakeholder. Tabel 11 menunjukkan ranking voice of customer hasil FGD dimensi acceptability.

Tabel 11. Ranking Voice Of Customer Hasil FGD Dimensi Acceptability

\begin{tabular}{lc}
\hline \multicolumn{1}{c}{ VOC } & Ranking \\
\hline $\begin{array}{l}\text { The Information System meets the } \\
\text { objective }\end{array}$ & 6 \\
\hline
\end{tabular}

Untuk dimensi customizeable dari hasil FGD dapat diketahui bahwa VOC User can edit personal data menjadi hal yang penting, namun bukan masuk ke prioritas utama bagi para stakeholder. Tabel 12 menunjukkan ranking voice of customer hasil FGD dimensi customizable.
Tabel 12. Ranking Voice Of Customer Hasil FGD Dimensi Customizable

\begin{tabular}{clc}
\hline No. & \multicolumn{1}{c}{ VOC } & Ranking \\
\hline 1 & $\begin{array}{l}\text { User can edit personal } \\
\text { data }\end{array}$ & 11 \\
2 & $\begin{array}{l}\text { User can find out the } \\
\text { data that had entered }\end{array}$ & 12 \\
\hline
\end{tabular}

Dari hasil FGD, untuk dimensi maintainability dapat diketahui bahwa dimensi maintainability tidak menjadi prioritas utama bagi para stakeholder. Tabel 13 menunjukkan ranking voice of customer hasil FGD dimensi maintainability.

Tabel 13. Ranking Voice Of Customer Hasil FGD Dimensi Maintainability

\begin{tabular}{clc}
\hline No. & \multicolumn{1}{c}{ VOC } & Ranking \\
\hline 1 & $\begin{array}{l}\text { The information system } \\
\text { is stable }\end{array}$ & 17 \\
2 & $\begin{array}{l}\text { The information system } \\
\text { is easy to maintain }\end{array}$ & 18 \\
\hline
\end{tabular}

Hasil dari FGD kemudian diurutkan dan diambil 5 peringkat teratas untuk dianalisis. Tabel 14 menunjukkan Ranking Voice of Customer hasil FGD. Hasil dari focus group discussion menyarankan agar "Service performance is reliable", "Information is realtime" dan "The Information System help organizational business process" adalah tiga peringkat teratas yang harus diprioritaskan ketika merancang sistem manajemen pengadaan laboratorium. Ketika VOC dipertimbangkan, maka rancangan sistem dapat dibuat spesifik untuk memenuhi ekspektasi stakeholder.

Tabel 14. Urutan Voice Of Customer Hasil FGD

\begin{tabular}{|c|c|c|c|}
\hline No. & VOC & Ranking & Dimensi \\
\hline 1 & Services performance is reliable & 1 & Reliability \\
\hline 2 & Information is real time & 2 & Reliability \\
\hline 3 & $\begin{array}{l}\text { The Information System help organizational business } \\
\text { process }\end{array}$ & 3 & Effectiveness \\
\hline 4 & The Information system can be accessed everywhere & 4 & Ease of use \\
\hline 5 & One data entry for all purpose & 5 & Efficiency \\
\hline 6 & The Information System meets the objective & 6 & Acceptability \\
\hline 7 & Information is believable & 7 & Reliability \\
\hline 8 & The information system allow users to access the content & 8 & Content \\
\hline 9 & Availability of troubleshooting service & 9 & Support \\
\hline 10 & Information provided is easy to understand & 10 & Content \\
\hline 11 & User can edit personal data & 11 & Customizable \\
\hline 12 & User can find out the data that had entered & 12 & Customizable \\
\hline 13 & The text is easy to read & 13 & Appearance \\
\hline 14 & The information system is unsightly & 14 & Appearance \\
\hline 15 & $\begin{array}{l}\text { The Information system can be accessed from other } \\
\text { platform }\end{array}$ & 15 & Ease of use \\
\hline 16 & The Newest's information notification is available & 16 & Ease of use \\
\hline 17 & The information system is stable & 17 & Maintainability \\
\hline 18 & The information system is easy to maintain & 18 & Maintainability \\
\hline 19 & The information system ability to safeguard & 19 & Security and privacy \\
\hline 20 & Availability of website usage information & 20 & Support \\
\hline 21 & The Information System is available in many languages & 21 & Ease of use \\
\hline
\end{tabular}




\section{B. Analisis Kebutuhan Sistem}

Untuk memenuhi VOC "Service performance is reliable" dan "Information is realtime", sangat jelas bahwa sistem informasi seharusnya mudah untuk diperbarui dan dapat diakses 24/7, karena hal tersebut maka sistem informasi ini harus berbentuk web-based. Langkah selanjutnya adalah membuat host dari web, setelah melakukan wawancara dengan kepala urusan laboratorium Fakultas Rekayasa Industri, aplikasi ini akan memiliki host di server milik fakultas karena fakultas memiliki server hosting yang bersifat privat serta dapat diakses dari manapun. Ketersediaan infrastruktur yang baik merupakan kunci dari kesuksesan sebuah sistem informasi. Urwiler dan Frolick (2011) menyatakan bahwa infrastruktur dan konektivitas merupakan fondasi dasar dari sebuah sistem informasi. Dengan adanya infrastruktur yang baik dan dapat diandalkan akan mempermudah dalam melakukan kegiatan pengadaan barang bagi laboratorium. Untuk memenuhi VOC "The Information System help organizational business process", sistem informasi seharusnya dirancang untuk memenuhi tujuan dari stakeholder. Wawancara bersama dengan 4 orang laboran di Fakultas Rekayasa Industri dilakukan untuk memperdalam hasil FGD terkait kebutuhan sistem. Dari hasil wawancara dengan laboran, merupakan hal penting bila sistem informasi dapat melacak kondisi langsung proses pengadaan dan skema yang dapat digunakan untuk membandingkan barang yang dipesan dengan barang yang sampai di laboratorium. Untuk masalah administratif dengan bagian logistik fakultas, penting untuk membuat permintaan pemesanan dari laboratorium secara elektronik. Dari hasil FGD maka dapat diketahui requirement awal untuk perancangan sistem informasi laboratiorium. Keseluruhan VOC yang telah dipilih oleh stakeholder kemudian dijadikan dasar pertimbangan dalam menentukan platform yang digunakan dalam merancang sistem informasi. Tabel 15 menunjukkan ringkasan kebutuhan yang diperlukan ketika merancang sistem. Agar rangking VOC 1-5 dapat diakomodir, maka sistem informasi yang dirancang harus dalam platform yang memungkinkan diakses kapan saja dan dimana saja terkait pengadaaan barang. Selain itu, dibutuhkan sistem yang mampu untuk mengelola keseluruhan kegiatan pengadaan yang terintegrasi antara tiap stakeholder.

Tabel 15. Ringkasan Kebutuhan Sistem

\begin{tabular}{ll}
\hline \multicolumn{1}{c}{ Platform } & \multicolumn{1}{c}{ Web-based } \\
\hline Host & $\begin{array}{l}\text { Server fakultas yang dapat diakses } \\
\text { dari luar }\end{array}$ \\
\hline Fungsi & - Surat pemesanan elektronik \\
Utama & - Pelacakan kondisi pengadaan \\
& - Membandingkan barang \\
\hline
\end{tabular}

Dari penelitian yang dilakukan oleh Mose, Nijhia dan Magutu (2013), diketahui bahwa merubah kebiasaan dan juga prosedur dari manual ke sebuah sistem membutuhkan waktu dan usaha yang besar. Maka dari itu dibutuhkan rencana perubahan secara bertahap agar nantinya sistem yang sudah dirancang dapat benar-benar $100 \%$ berfungsi dan bermanfaat bagi pihak fakultas. Pelatihan menjadi hal yang penting yang harus dilakukan agar sistem informasi yang dibangun dapat digunakan oleh semua pengguna dengan baik. Resistensi pasti akan terjadi di awal karena baik pihak laboratorium maupun fakultas tidak terbiasa menggunakan bantuan sistem informasi, diperlukan dukungan dari manajemen puncak agar hal tersebut dapat diatasi dengan baik. Manajemen puncak yang dimaksud bisa dari pejabat struktural setingkat asisten manajer atau yang lebih tinggi. Dukungan manajemen puncak dapat berbentuk penugasan ataupun instruksi kerja/standar agar pengguna yang berkepentingan menggunakan sistem yang akan dirancang.

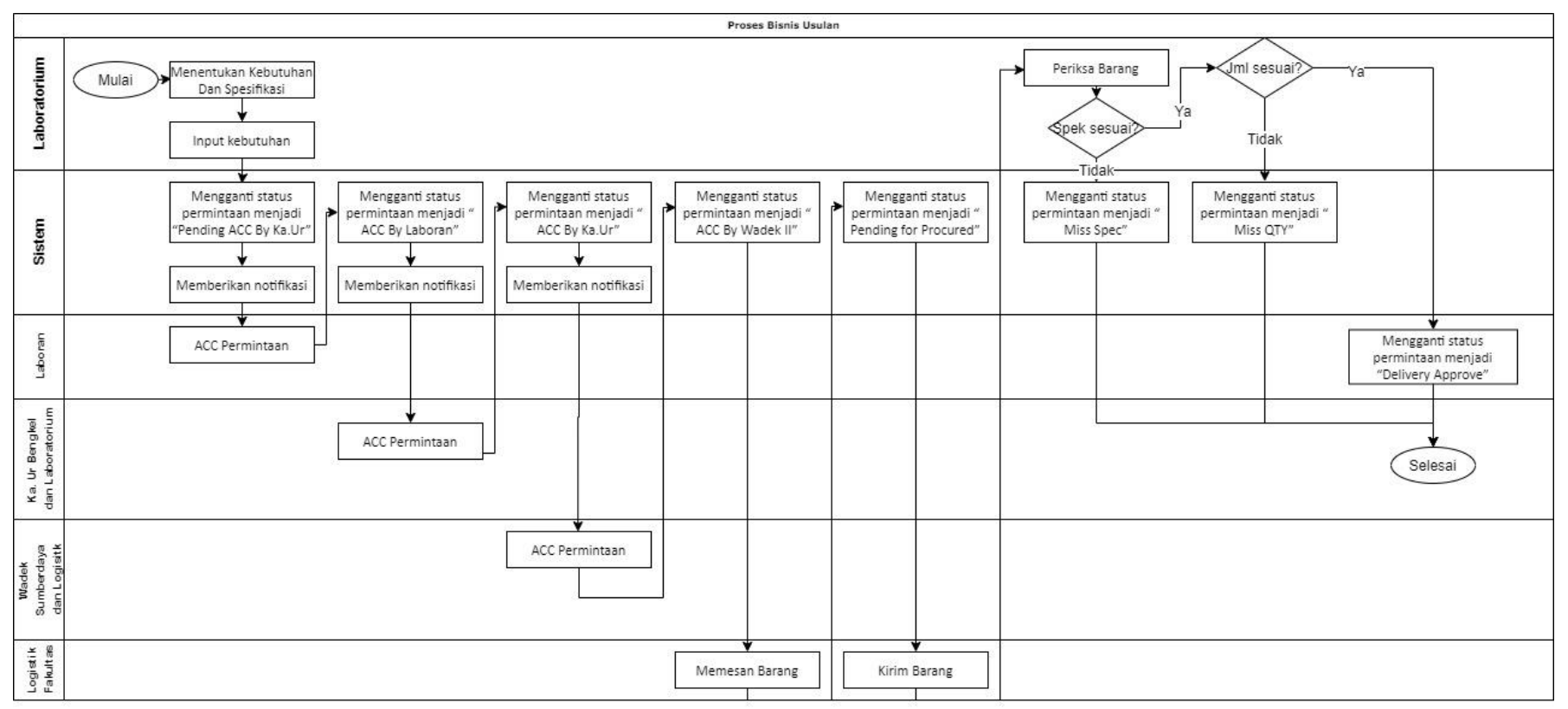

Gambar 4. Proses Bisnis Usulan 


\section{Kesimpulan}

Tujuan dari penelitian ini adalah untuk merancang kebutuhan sistem manajemen pengadaan laboratorium yang dapat memenuhi ekspektasi pelanggan dan stakeholder. Dalam penelitian ini, dimensi kualitas digunakan untuk menentukan spesifikasi dari karakter sistem informasi menggunakan dimensi kualitas Soesanto dkk. (2013) dan voice of customer dari Soesanto dkk. (2014), (2016). Dari hasil focus group discussion, dapat disimpulkan bahwa dalam merancang sistem manajemen pengadaan laboratorium, platform yang digunakan adalah web-based dan menggunakan server fakultas sebagai host. Fungsi atau fitur utama dari sistem ini adalah pengadaan secara elektronik, melacak kondisi pengadaan dan membandingkan barang. Penelitian lebih lanjut dibutuhkan untuk memecah kembali voice of customer menjadi karakteristik teknis untuk kebutuhan analisis yang lebih spesifik dan hasil dari penelitian ini dapat digunakan untuk merancang sistem informasi pengadaan laboratorium.

\section{Daftar Pustaka}

Ahmadi, A., Pishvaee, M., \& Torabi, S. (2018). Procurement Management in Healthcare Systems. In Operations Research Applications in Health Care Management (pp. 569-598). Cham: Springer.

Daellenbach, H., \& McNickle, D. (2013). Management Science: Decision-making Through Systems Thinking. Palgrave Macmillan.

Laudon, K., \& Laudon, j. (2016). Managing Information System: Managing the Digital Firm. Essex: Pearson.

Mose, J., Njihia, J., \& Magutu, P. (2013). THE CRITICAL SUCCESS FACTORS AND CHALLENGES IN E-PROCUREMENT ADOPTION AMONG LARGE SCALE MANUFACTURING FIRMS IN NAIROBI, KENYA. European Scientific Journal, 9(13), 375-401.

O'Brien, J., \& Marakas, G. (2012). Management Information System. New York: McGraw-Hill.

Pérez-Méndez, J., \& Machado-Cabezas, Á. (2014). Relationship between management information systems and Corporate Performance. Spanish Acccoutning Review.

Petter, S., DeLone, W., \& Mclean, E. (2008). Measuring information systems success: models, dimensions, measures, and interrelationships. European Journal of Information Systems, 17, 236-263.

Saxena, S., \& Agarwal, D. (2018). A Critical Literature Survey on Factors that Effecting E-Procurement Software. International Journal of Advanced Research in Computer Engineering \& Technology, 7(1), 78-82.

Seo, D., Tan, C.-W., \& Warman, G. (2018). Vendor satisfaction of E-government procurement systems in developing countries: an empirical research in Indonesia. Information Technology for Development, 1-28.
Sharma, S., \& Pandey, S. (2016). Revisiting Requirement Analysis Techniques and Challenges. Soft Computing: Theories and Applications 2016. Jaipur.

Soesanto, R. P., Kurniawati, A., \& Iqbal, M. (2016). MEASURING

LABORATORY

ADMINISTRATION SYSTEM SATISFACTION : A CASE STUDY. 9th International Seminar on Industrial Engineering and Management. Padang.

Soesanto, R. P., Utama, M. S., \& Kurniawati, A. (2013). Pengukuran Kualitas Sistem Informasi Laboratorium. Industrial Engineering Conference on Telecommunication. Bandung: Telkom University.

Soesanto, R., Utama, M., \& Kurniawati, A. (2014). Quality Function Deployment for Laboratory Management Information System. TIME-E. Bandung: Bandung Institute of Technology.

Sommerville, I. (2009). Software Engineering. Essex: Pearson.

Turban, E., Aronson, J., \& Liang, T.-P. (2005). Decision Support and Intelligence System. New Jersey: Prentice Hall.

Urwiler, R., \& Frolick, M. (2011). The IT Value Hierarchy: Using Maslow's Hierarchy of Needs as a Metaphor for Gauging the Maturity Level of Information Technology Use within Competitive Organizations. Information Systems Management, 25, 83-88. 